\title{
Determining the level of physical activity estimated by the Canada Fitness Survey questionnaire using criteria of the International Physical Activity Questionnaire
}

\author{
Alicja Kostencka ${ }^{1}$, Anna Pastuszak², Krzysztof Buśko ${ }^{1}$ \\ ${ }^{1}$ Department of Biomedical Basis of Physical Culture, Kazimierz Wielki University, Bydgoszcz, Poland; ${ }^{2}$ Department of \\ Biomechanics, Institute of Sport - National Research Institute, Warsaw, Poland
}

\section{Summary}

Study aim: The aim of the study was to determine the weekly energy expenditure measuring MET/min/week based on data collected through the Canada Fitness Survey (CFS), according to the classification used in the International Physical Activity Questionnaire (IPAQ), and to verify the adopted method to assess the level of physical activity in students of physical education.

Material and methods: The study involved 116 female students (21.1 \pm 1.6$)$ and 276 male students (21.2 \pm 1.7$)$, studying Physical Education at Kazimierz Wielki University. Physical activity (PA) of respondents assessed using the Canada Fitness Survey was converted to energy expenditure in MET/min/week using the criteria established in the IPAQ. Body composition was assessed according to bioelectrical impedance.

Results: A significantly smaller fat fraction was observed in the group of students with high physical activity (PA) (p < 0.01$)$. In women, there was a significant relation between FAT\% and all analysed characteristics of physical activity: total physical activity (TPA) -0.274 , vigorous intensity (VI) -0.216 , number of days spent on physical activity (DTPA) - 0.199 and number of days spent on vigorous intensity (DVI) $-0.202(\mathrm{p}<0.05)$. In men, a significant relation was found between all the analysed tissue components and the adopted variables of PA (FAT\% vs. TPA -0.145 , VI -0.203 , DTPA -0.187 ; FATkg vs. TPA 0.123 , VI -0.186 , DTPA - 0.178; FATkg vs. DVI - 0.131). BMI significantly correlated with VI ( -0.162$)$ and DVI (-0.140), $\mathrm{p}<0.05$.

Conclusions: Based on data collected using the CFS on the type and frequency of PA during a week, we can determine the level of activity in a measurable way, using the IPAQ classification. There is a significant relationship between thus determined physical activity levels and body composition in both women and men, which proves the accuracy of the adopted method of converting weekly energy expenditure to $\mathrm{MET} / \mathrm{min} /$ week.

Keywords: Physical activity - International Physical Activity Questionnaire (IPAQ) - Canada Fitness Survey (CFS) - Body composition - Students

\section{Introduction}

PA and nutrition are modifiable elements of lifestyle, the improvement of which may reduce the incidence of many metabolic-civilization diseases [31]. Standardizing testing procedures and creating the conditions for conducting international comparative analysis of the collected empirical data relating to various elements of lifestyle and health of the population, with particular emphasis on aspects related to PA, can contribute to the identification of environmental pathogens [16]. Selection of an appropriate method of PA studies is complicated, and it depends on many different conditions [1]. In population studies on lifestyle, including PA, the use of diagnostic surveys is popular. Questionnaires filled in independently by respondents, conducted by pollsters or supported by video clips, are typically used for subjective assessment of the level of PA. The questionnaires to measure physical activity are still being upgraded and modified, their accuracy and reliability are being confirmed, and new solutions are being implemented based on systematically obtained results of previous studies [28]. 
In recent years, one of the questionnaires most frequently used in Europe is the International Physical Activity Questionnaire (IPAQ). However, opinions on the research tool differ. On the one hand, some authors confirm the consistency of test results obtained through the use of IPAQ with the results obtained by objective methods, such as measurement with an accelerometer $[11,20]$. On the other hand, there are publications containing allegations related to the disturbing influence of important factors, e.g. the level of respondents' fitness to the reliability of the results in the IPAQ [27] and related to revaluation [23], as observed in the Polish population in the case of the extended version of the IPAQ [4].

Selection of the appropriate questionnaire to study the PA of a particular population is therefore very important. Questionnaires used in children are different from those used in adults and in the elderly [15]. Based on the answers given, it is possible to collect quantitative information on participation in different types of activity and to determine its frequency $[7,12,26]$, to calculate the total daily or weekly energy expenditure $[5,25]$ or express the energy expended on each of the activities given by respondents in the MET measure [2]. These measurable ways to calculate physical activity are nowadays most often used in international $[3,10,21,22,32)$ and intra-population comparisons $[6,13$, 29 ] to identify groups that are least physically active.

The Canada Fitness Survey (CFS) questionnaire was the most popular tool for estimating fitness or physical activity levels of Canadians. A huge survey carried out in the early nineteen eighties included 4,831 men and 5,448 women. It consisted of 13500 households - a nationally representative sample of the Canadian population [8].

Information collected on the basis of the CFS was compiled with data acquired using various questionnaires used in the UK, Canada and the United States to compare percentages of people with impaired relative weight in age categories from 20 to 64 years [30]. Using a questionnaire previously published for the British survey, the Canadian and United States data were analysed and the prevalence of excessive weight was compared for particular ages [30]. On the basis of the data collected through the CFS questionnaire, concerning elements of lifestyle in relation to social status, factors for cardiovascular disease in women and men were also identified $[16,26]$.

The Canada Fitness Survey has two components: a questionnaire on health and lifestyle and a physical measures component. The extended version allows one to also obtain information on physical activity of the respondents, and other demographic features. Questions included in the section on lifestyle allow us to characterize the type and frequency of physical activity undertaken in a week, during the last month and last year. In the CFS physical activity level was defined on the basis of leisuretime activity. Subjects who reported that they engaged in physical activity for less than 3 hours per week for less than 9 months of the year were defined as sedentary [7].

Determination of the level of physical activity in a measurable manner with the CFS questionnaire (MET measure) facilitates the use of data for comparisons between populations in space and time, which can contribute to the search for pathogenic factors of many diseases associated with elements of lifestyle.

The aim of the study was to determine the weekly energy expenditure measuring MET/min/week based on data collected through the Canada Fitness Survey (CFS), according to the classification used in the International Physical Activity Questionnaire (IPAQ) and verification of the adapted method to assess the level of physical activity in Polish students of physical education.

\section{Material and methods}

The study involved 116 female students and 276 male students of physical education at Kazimierz Wielki University in Bydgoszcz. The characteristics of the groups are presented in tables 1 and 2. The physical activity was evaluated with the Canada Fitness Survey (CFS) questionnaire. Information on activities undertaken during the last week were converted to MET/min/week loads. To facilitate the identification of zones of intensity of physical activity, the CFS questionnaire used examples of typical exercise with different levels of intensity [2, 24]. Applying the IPAQ criteria, students were assigned to three levels of physical activity: insufficient, sufficient and high [5]. Body composition was evaluated by electric bioimpedance (BIA) with the Tanita BC 418 MA device (Japan). In order to assess the accuracy of the division adopted from IPAQ to the CFS questionnaire, the tissue composition of students with different levels of physical activity was evaluated.

A two-way analysis of variance (ANOVA) examined the main effects of sex and physical activity, and one-way analysis between physical activity levels. The significance of differences between means was evaluated post hoc with Scheffe's test. The effect size (ES) in ANOVA was evaluated by eta square and interpreted as follows: $0.01 \leq \eta^{2}<0.06$ small, $0.06 \leq \eta^{2}<0.14$ medium and $\eta^{2} \geq 0.14$ large [9]. Pearson's correlation coefficient was used to evaluate correlations between all parameters. For the statistical analyses, the value of $\alpha=0.05$ was considered as significant. All computations were performed with STATISTICA software (v. 12.0, StatSoft, USA).

\section{Results}

Table 1 presents the results for female students of physical education in categories of physical activity adapted 
Table 1. Mean $( \pm \mathrm{SD})$ values of anthropometric characteristics and physical activity in the three groups of women

\begin{tabular}{|c|c|c|c|c|c|c|c|}
\hline Variables & $\begin{array}{c}\text { Total, } \mathrm{n}=116 \\
100 \%\end{array}$ & $\begin{array}{c}\text { INSA, } \mathrm{n}=27 \\
23.3 \%\end{array}$ & $\begin{array}{l}\mathrm{SA}, \mathrm{n}=53 \\
\quad 45.7 \%\end{array}$ & $\begin{array}{l}\mathrm{HA}, \mathrm{n}=36 \\
31.0 \%\end{array}$ & $\mathrm{~F}$ & $\mathrm{p}$ & $\eta^{2}$ \\
\hline Age [years] & $21.1 \pm 1.6$ & $21.3 \pm 1.5$ & $21.0 \pm 1.5$ & $21.0 \pm 1.7$ & 0.429 & 0.652 & 0.008 \\
\hline Height [cm] & $168.0 \pm 6.6$ & $168.9 \pm 9.0$ & $167.4 \pm 6.0$ & $168.2 \pm 5.6$ & 0.430 & 0.652 & 0.008 \\
\hline Body mass [kg] & $61.5 \pm 9.5$ & $63.0 \pm 11.9$ & $61.1 \pm 10.0$ & $61.1 \pm 6.6$ & 0.426 & 0.654 & 0.007 \\
\hline BMI index $\left[\mathrm{kg} \cdot \mathrm{m}^{-2}\right]$ & $21.6 \pm 3.2$ & $22.0 \pm 3.0$ & $21.8 \pm 3.0$ & $21.0 \pm 3.7$ & 0.903 & 0.408 & 0.016 \\
\hline $\operatorname{FAT}_{\mathrm{BIA}}[\%]$ & $24.8 \pm 5.7$ & $26.8 \pm 4.9$ & $25.3 \pm 5.9$ & $22.7 \pm 5.6^{\mathrm{a}}$ & 4.649 & 0.011 & 0.076 \\
\hline $\mathrm{FAT}_{\mathrm{BIA}}[\mathrm{kg}]$ & $15.7 \pm 6.1$ & $17.4 \pm 6.7$ & $15.9 \pm 6.7$ & $14.1 \pm 4.4$ & 2.373 & 0.098 & 0.040 \\
\hline $\mathrm{FFM}_{\mathrm{BIA}}[\mathrm{kg}]$ & $45.9 \pm 4.7$ & $45.6 \pm 5.6$ & $45.2 \pm 4.5$ & $47.0 \pm 3.9$ & 1.743 & 0.180 & 0.030 \\
\hline $\begin{array}{l}\text { Total physical activity } \\
\text { (TPA) [MET/min/week] }\end{array}$ & $2491.8 \pm 1420.2$ & $1002.8 \pm 454.1$ & $2289.8 \pm 922.7^{\mathrm{a}}$ & $3905.8 \pm 1175.1^{\mathrm{ab}}$ & 77.282 & 0.000 & 0.578 \\
\hline $\begin{array}{l}\text { Number of days spent } \\
\text { on physical activity } \\
\text { (DTPA) [-] }\end{array}$ & $3.1 \pm 1.0$ & $1.6 \pm 0.5$ & $3.3 \pm 0.5^{\mathrm{a}}$ & $3.9 \pm 0.4^{\mathrm{ab}}$ & 195.808 & 0.000 & 0.776 \\
\hline $\begin{array}{l}\text { Vigorous intensity (VI) } \\
{[\mathrm{MET} / \mathrm{min} / \text { week] }}\end{array}$ & $965.8 \pm 716.5$ & $342.8 \pm 224.4$ & $631.1 \pm 286.0^{\mathrm{a}}$ & $1925.8 \pm 333.2^{\mathrm{ab}}$ & 296.526 & 0.000 & 0.840 \\
\hline $\begin{array}{l}\text { Number of days spent } \\
\text { on vigorous intensity } \\
\text { (DVI) [-] }\end{array}$ & $2.7 \pm 1.3$ & $1.5 \pm 0.8$ & $2.1 \pm 0.9^{\mathrm{a}}$ & $4.3 \pm 0.5^{\mathrm{ab}}$ & 127.197 & 0.000 & 0.692 \\
\hline
\end{tabular}

INSA - insufficient activity, SA - sufficient activity, HA - high activity; ${ }^{\mathbf{a}}$ - significantly different from INSA, $\mathrm{p}<0.05,{ }^{\mathrm{b}}-$ significantly different from SA, $\mathrm{p}<0.05$.

Table 2. Mean $( \pm \mathrm{SD})$ values of anthropometric characteristics and physical activity in the three groups of men

\begin{tabular}{|c|c|c|c|c|c|c|c|}
\hline Variables & $\begin{array}{c}\text { Total, } \mathrm{n}=276 \\
100 \%\end{array}$ & $\begin{array}{c}\text { INSA, } \mathrm{n}=28 \\
10.2 \%\end{array}$ & $\begin{array}{c}\mathrm{SA}, \mathrm{n}=132 \\
47.8 \%\end{array}$ & $\begin{array}{l}\mathrm{HA}, \mathrm{n}=116 \\
\quad 42.0 \%\end{array}$ & $\mathrm{~F}$ & $\mathrm{p}$ & $\eta^{2}$ \\
\hline Age [years] & $21.2 \pm 1.7$ & $21.2 \pm 1.7$ & $21.3 \pm 1.9$ & $21.1 \pm 1.5$ & 0.559 & 0.572 & 0.004 \\
\hline Height $[\mathrm{cm}]$ & $180.8 \pm 6.9$ & $179.1 \pm 8.2$ & $180.4 \pm 6.8$ & $181.6 \pm 6.5$ & 1.900 & 0.152 & 0.014 \\
\hline Body mass $[\mathrm{kg}]$ & $77.5 \pm 9.3$ & $73.9 \pm 8.6$ & $78.8 \pm 9.3^{\mathrm{a}}$ & $76.8 \pm 9.2$ & 3.754 & 0.025 & 0.027 \\
\hline BMI index $\left[\mathrm{kg} \cdot \mathrm{m}^{-2}\right]$ & $23.7 \pm 2.3$ & $23.0 \pm 2.5$ & $24.2 \pm 2.3$ & $23.3 \pm 2.2^{b}$ & 6.490 & 0.002 & 0.045 \\
\hline $\operatorname{FAT}_{\mathrm{BIA}}[\%]$ & $12.5 \pm 4.3$ & $12.2 \pm 4.9$ & $13.3 \pm 4.1$ & $11.5 \pm 4.3^{b}$ & 5.669 & 0.004 & 0.040 \\
\hline $\mathrm{FAT}_{\mathrm{BIA}}[\mathrm{kg}]$ & $9.8 \pm 4.1$ & $9.2 \pm 4.2$ & $10.7 \pm 4.1$ & $9.0 \pm 4.0^{\mathrm{b}}$ & 5.871 & 0.003 & 0.041 \\
\hline $\mathrm{FFM}_{\mathrm{BIA}}[\mathrm{kg}]$ & $67.6 \pm 7.1$ & $64.8 \pm 7.3$ & $68.1 \pm 6.8$ & $67.8 \pm 7.3$ & 2.634 & 0.074 & 0.019 \\
\hline $\begin{array}{l}\text { Total physical activity } \\
\text { (TPA) [MET/min/week] }\end{array}$ & $2955.5 \pm 1378.1$ & $1127.1 \pm 687.9$ & $2422.5 \pm 908.4^{\mathrm{a}}$ & $4003.3 \pm 1114.8^{\mathrm{ab}}$ & 133.735 & 0.000 & 0.495 \\
\hline $\begin{array}{l}\text { Number of days spent } \\
\text { on physical activity } \\
\text { (DTPA) [-] }\end{array}$ & $3.5 \pm 0.7$ & $1.9 \pm 0.4$ & $3.5 \pm 0.5^{\mathrm{a}}$ & $3.8 \pm 0.4^{\mathrm{ab}}$ & 197.196 & 0.000 & 0.591 \\
\hline $\begin{array}{l}\text { Vigorous intensity (VI) } \\
{[\mathrm{MET} / \mathrm{min} / \text { week }]}\end{array}$ & $1202.9 \pm 662.7$ & $476.6 \pm 286.3$ & $744.0 \pm 249.9^{\mathrm{a}}$ & $1900.4 \pm 314.4^{\mathrm{ab}}$ & 620.911 & 0.000 & 0.820 \\
\hline $\begin{array}{l}\text { Number of days spent } \\
\text { on vigorous intensity } \\
\text { (DVI) [-] }\end{array}$ & $3.1 \pm 1.3$ & $1.7 \pm 0.9$ & $2.3 \pm 0.9^{\mathrm{a}}$ & $4.3 \pm 0.5^{\mathrm{ab}}$ & 276.543 & 0.000 & 0.670 \\
\hline
\end{tabular}


from IPAQ: high, sufficient and insufficient level. There were significant differences observed between the groups in total physical activity performed in a week (total physical activity - TPA) and intensive activity (vigorous intensity - VI) expressed in MET/min/week and the number of days in which it was performed $(p<0.01)$. It was found that the percentage of total fat in the body composition of female students with a high level of physical activity (3905.8 $\pm 1175.1 \mathrm{MET} / \mathrm{min} /$ week) was on average $4.1 \%$ smaller $(\mathrm{p}<0.01)$ compared to their colleagues in whom the level was insufficient $(2491.8 \pm 1420.2 \mathrm{MET} / \mathrm{min} /$ week). Along with the decline in physical activity levels in women, there was an increase in the value of body mass index (BMI from 21.0 to 22.0) and percentage of body fat in their body composition (from $22.7 \%$ to $26.8 \%$ ). In female students there was a significant association between FAT $\%$ and all analysed characteristics of physical activity (TPA MET/min/week - 0274, vigorous intensity (VI) - 0216 and the number of days spent on these activities per week, respectively - 0199 (DTPA) and - 0202 (DVI), $\mathrm{p}<0.05$.

Table 2 presents the characteristics of physical activity and tissue composition of students. In the groups of men differentiated regarding physical activity, there were significant differences in the average values of TPA, DTPA, VI and DVI $(\mathrm{p}<0.001)$. Students with high physical activity had a significantly lower percentage of fat in the body composition compared to the group with a sufficient level $(\mathrm{p}<0.01)$, whereas men with a sufficient level of physical activity had the heaviest weight. Their average body weight differed significantly only compared to the men with insufficient physical activity $(\mathrm{p}<0.01)$. In male students, a significant association was found between all the components of the tissue analysed and the adopted variables of physical activity (FAT\% vs. TPA -0.145 , VI -0.203 and DTPA -0.187 ; FATkg correlated with TPA -0.123 , VI -0.186 and DTPA - 0.178; FFMkg vs. DVI $0.131)$. BMI significantly correlated with intensive activity (VI) and number of days during which it was practised (DVI), respectively -0.162 and $-0.140(p<0.05)$.

\section{Discussion}

Unification of testing procedures in order to conduct multi-dimensional analysis of empirical data for the purposes of identification of pathogens is a very important element of the epidemiological strategies pursued by the WHO [31]. The data collected in time make it possible to track changes in successive generations, as well as to identify the pathogenic factors $[13,26]$. Differences in the test or protocols used make direct comparisons difficult, and the results are not comparable. Determining the direction and intensity of the observed trends is possible when the compared data concern the same sex and population of the same age, and the material was collected according to a similar test method. Such methodological constraints were used to show the trend of overweight and obesity in the adult US population [14] and in order to compile groups at risk of overweight and obesity in the United Kingdom, Canada and the United States [30].

The extensive material used for the analysis was collected over the years with various questionnaires: Canada Fitness Survey (CFS), Canadian Health Measures Survey (CHMS), Canadian Physical Activity, Fitness and Lifestyle Approach (CPAFLA) and the Physical Activity Readiness Questionnaire (PAR-Q). It was only after the application of a unified method that the data could be compared [26]. The converter rate adapted from the IPAQ to determine physical activity in the CFS, verified by analysing the composition of the body tissue in the examined students of physical education, can be an effective tool used in similar comparisons. Accuracy of the division into three levels of physical activity depending on the BMI of respondents used in IPAQ has already been confirmed in the work by Biernat and Tomaszewski [6]. In the studies on students from selected universities in Warsaw, it was found that in the group with high levels of physical activity, there were only people with normal relative weight. In analyses of body composition in young training people, increased BMI does not indicate an increased fraction of fat in body composition [18], but it is a good predictor of fat in an average population [19]. Probably for this reason, there was no greater relationship between the weight-height proportions and the level of activity of the surveyed students of physical education, whereas this correlation was confirmed in relation to the fraction of fat in body composition (especially in women). The CFS information declared by the respondents, concerning the length and intensity of efforts in a week and converted into metabolic equivalents of work (METs), according to the procedure used in the IPAQ [24], allowed the calculation of average energy expenditure for women at 2492 $\mathrm{MET} / \mathrm{min} / \mathrm{week}$ and for men at $2956 \mathrm{MET} / \mathrm{min} /$ week. These data are consistent with the weekly workload that was found in students of the Warsaw Academy of Physical Education using the IPAQ, in terms of gender (women 2470 and men $4034 \mathrm{MET} / \mathrm{min} /$ week) [21], and in students of similar studies in Beijing (respectively 1982 and 2843 $\mathrm{MET} / \mathrm{min} /$ week) [32].

The compared students constitute a population of physically active people, whose learning programme includes compulsory sports classes. However, the differences in the level of activity depend largely on the involvement in sports activities associated with practising sports. This is probably the reason why a review of sources also revealed significantly higher mean MET values for activities undertaken in a week by students of physical education at 
Charles University in Prague (women 10964, men 9525 $\mathrm{MET} / \mathrm{min} /$ week) [21] and Olomulcu (respectively 5296 and $6456 \mathrm{MET} / \mathrm{min} /$ week) [32], as well as in female students (mostly players) from Poznan [28]. According to the classification adopted in the paper, a high level of physical activity was found in $38.8 \%$ of subjects ( $42 \%$ of men and $31 \%$ of women), a sufficient level in $47.2 \%$ (respectively 47.8 and $45.7 \%$ ) and a unsufficient level in 14\% (in terms of gender $10.2 \%$ and $23.3 \%$ ). It seems alarming that there was a high percentage of people who do not meet even the conditions for a sufficient level although similar fractions in the population studying physical education have been identified in Beijing (12\% of female students and 19\% of male students) [32]. In other reports determining the level of physical activity in this group of students, the percentages of people with insufficient levels of physical activity ranged only from $2.4 \%$ to $5.5 \%$ in men and $6.2 \%$ in women [21,32]. In contrast, this type of study using the IPAQ conducted among low-activity students of the humanities at the University of Silesia also showed less than $2.5 \%$ of women and $1.5 \%$ of men with the lowest levels of activity [17]. Therefore, adopting a measurable way of determining the physical activity from the IPAQ to the CFS seems to be accurate, and the recalculated information on the activities undertaken in a week can be analysed over time and referred to other aspects of lifestyle and health of the respondents.

\section{Conclusions}

Based on data collected using the Canada Fitness Survey (CFS) on the type and frequency of physical activity during a week, we can determine the level of activity in a measurable way, using the IPAQ classification. There is a significant relationship between thus determined physical activity levels and body composition in both women and men, which proves the accuracy of the adopted method of converting weekly energy expenditure to MET/min/ week.

\section{References}

1. Ainsworth B.E., L. Cahalin, M. Buman, R. Ross (2015) The current state of physical activity assessment tools. Prog. Cardiovasc. Dis., 57(4): 387-395, DOI: 10.1016/j. pcad.2014.10.005. Epub 2014 Oct 31.

2. Ainsworth B.E., W.L. Haskell, M.C. Whitt, M.L. Irwin, A.M. Swartz, S.J. Strath, W.L. O'Brien, D.R. Bassett Jr., K.H. Schmitz, P.O. Emplaincourt, D.R. Jacobs Jr., A.S. Leon (2000) Compedium of physical activities: an update of activity codes and MET intensities. Med. Sci. Sports Exerc., 32(9): 498-516.
3. Bauman A., B.E. Ainsworth, J.F. Sallis, M. Hagströmer, C.L. Craig, F.C. Bull, M. Pratt, Kamalesh Venugopal, J. Chau, M. Sjöström (2011) The descriptive epidemiology of sitting. A 20-country comparison using the International Physical Activity Questionnaire (IPAQ). Am. J. Prev. Med., 41(2): 228-235, DOI:10.1016/j. amepre.2011.05.003.

4. Biernat E., M. Piątkowska (2016) Overestimation of physical activity by long IPAQ in a Polish nationwide study. Hygeia Public Health, 51(1): 87-95.

5. Biernat E., R. Stupnicki, A.K. Gajewski (2007) International Physical Activity Questionnaire (IPAQ) - Polish version [in Polish]. Phys. Edu. Sport, 51(1): 47-54.

6. Biernat E., W. Tomaszewski (2012) The relationship between physical activity and body mass index in Warsaw students. Polish J. Sports Med., 3(4): 197-206, DOI:10.5604/1232406X.1028042

7. Canada Fitness Survey (1983) A User's Guide to CFS Findings, Ottawa.

8. Canada Fitness Survey (1983). Fitness and lifestyle in Canada. Ottawa.

9. Cohen J. (1988) Statistical power analysis for the behavioral sciences (2nd ed.). Hillsdale, NJ: Erlbaum.

10. Craig C.L., A.L. Marshall, M. Sjöström, A.E. Bauman, M.L. Booth, B.E. Ainsworth, M. Pratt, U. Ekelund, A. Yngve, J.F. Sallis, P. Oja (2003) International Physical Activity Questionnaire: 12-country reliability and validity. Med. Sci. Sport Exerc., 35(8): 1381-1395.

11. Curry W.B., J.L. Thompson (2015) Comparability of accelerometer - and IPAQ-derived physical activity and sedentary time in South Asian women: A crosssectional study. Eur. J. Sport Sci., 15(7): 655-662, DOI: 10.1080/17461391.2014.957728. Epub 2014 Sep 24.

12. Gratton Ch., N. Rowe, A.J. Veal (2011) International Comparisons of Sports participation in European Countries: an Update of the COMPASS., Project Eur. J. Sport Society 8(1/2): 99-116.

13. Klimczyk M., M. Stec (2014) The physical and motor development of 9-year-old children attending football classes in "Footbal school for children". Pedagogika, Psihologia ta Mediko-Biologicni Problemi Fizicnogo Vihovanna i Sportu - 2014, no. 12, pp. 65-69.

14. Li C., E.S. Ford, L.S. Mc Guire, A.H. Mokdad (2007) Increasing trends in waist circumference and abdominal obesity among U.S. adults. Obesity 15(1): 216-224.

15. Lipert A., A. Jegier (2009) The measurement of physical activity. Polish J. Sport Med., 25(3): 155-168.

16. Millar W.J., D.T. Wigle (1986) Socioeconomic disparities in risk factors for cardiovascular disease. CMAJ: Can. Med. Assoc. J., 134(2): 127-132.

17. Mynarski W., M. Rozpara, K. Czapla, W. Garbaciak (2009) Aerobic capacity of students with different levels of physical activity assessed by IPAQ. J. Hum. Kin., 21: 89-96. 
18. Nevill A.M., E.M. Winter, S. Ingham, A. Watts, G.S. Metsios, A.D. Stewart (2010) Adjusting athletes' body mass index to better reflect adiposity in epidemiological research. J. Sports Sci., 28: 1009-1016, DOI: 10.1080/02640414.2010.487071.

19. Ortega F.B., X. Sui, C.J. Lavie, S.N. Blair (2016) Body Mass Index, the most widely used but also widely criticized index: Would a criterion standard measure of total body fat be a better predictor of cardiovascular disease mortality? Mayo Clinic Proceedings, 91(4): 443-455.

20. Oyeyemi A.L., M. Umar, F. Oguche, S.U. Aliyu, A.Y. Oyeyemi (2014) Accelerometer-determined physical activity and its comparison with the International Physical Activity Questionnaire in a sample of Nigerian adults. PLoS One, 28; 9(1): e87233, DOI: 10.1371/journal. pone.0087233. eCollection 2014.

21. Pastuszak A., K. Lisowski, J. Lewandowska, K. Buśko (2014) Level of physical activity of physical education students according to criteria of the IPAQ questionnaire and the recommendations of WHO experts. Biomed. Hum. Kinet., 6: 5-11.

22. Piątkowska M. (2010) Participation of Polish in the physical activity in comparing to other countries of the European Union. [in Polish]. In: Buśko K., J. Charzewska, K. Kaczanowski (eds). Contemporary testing methods of the activity, the efficiency and the physical fitness of the human. AWF Warszawa, pp 38-57.

23. Scholes S., S. Bridges, L. Ng Fat, J.S. Mindell (2016) Comparison of the Physical Activity and Sedentary Behaviour Assessment Questionnaire and the Short-Form International Physical Activity Questionnaire: An Analysis of Health Survey for England Data. PLoS One. 18; 11(3): e0151647, DOI: 10.1371/journal.pone.0151647. eCollection 2016.

24. Scoring protocol. www.ipaq.ki.se

25. Seven - Day Physical Activity Recall (1997) Med. Sci. Sport and Exerc., 29(suppl. 6): 89-103.

26. Shields M., M.S. Tremblay, M. Laviolette, L. Cora, C.L. Craig, I. Janssen, S.C. Gorber (2010) Fitness of Canadian adults: Results from the 2007-2009. Canadian
Health Measures Survey Statistics Canada, Catalogue no. 82-003-XPE, Health Report., 21(1).

27. Shook R.P., N.C. Gribben, G.A. Hand, A.E. Paluch, G.J. Welk, J.M. Jakicic, B. Hutto, S. Burgess, S.N. Blair (2016) Subjective Estimation of Physical Activity Using the International Physical Activity Questionnaire Varies by Fitness Level. J. Phys. Act. Health, 13(1): 79-86, DOI: 10.1123/jpah.2014-0543. Epub 2015 Apr 21.

28. Silsbury Z., R. Goldsmith, A. Rushton (2015) Systematic review of the measurement properties of self-report physical activity questionnaires in healthy adult populations. BMJ Open, 15; 5(9): e008430, DOI: 10.1136/bmjopen2015-008430.

29. Sokołowski M., A. Kaiser, A. Čepulènas (2010) Physical activity of female students of the University School of Physical Education in Poznań on the basis of IPAQ educational and social perspectives. Ugdymas Kuno Kultura Sportas 3(78): 90-95.

30. Wayne J., M.A. Milar, T. Stephens (1987) The Prevalence of Overweight and Obesity in Britain, Canada, and United States. Am. J. Public Health, 77: 38-41.

31. World Health Organization (2003) Integrated prevention of noncommunicable diseases. Draft global strategy on diet, physical activity and health. EB 113/44 Add. 1, 8-18, Geneva.

32. Zaho Y., E. Sigmund, D. Sigmundová, L. Yan (2007) Comparison of Physical Activity between Olomouc and Beijing university students using and International Physical Activity Questionnaire. Acta Univ. Palacki Olomuc, Gymn., 37(4): 107-114.

\section{Received 23.09.2016 \\ Accepted 03.11.2016}

(C) University of Physical Education, Warsaw, Poland

Acknowledgments

The study was made in research projects Kazimierz Wielki University. 